\title{
소녀들의 보다 나은 삶 \\ (Better Life for Girls, BLG) 구상과 보건
}

목차

I. 서론

제 $\mathrm{I}$ 장

II. 대상 인구

III. 여성 청소년의 보건 문제들

1. 생식보건의 개념 및 영역

2. 여성청소년 출산

3. 여성 청소년의 기타 보건 문제들

4. 여성 성기 절단(Female Genital Cutting, FGC)

5. 청소년 친화적 서비스(Youth-friendly services)

6. 생식보건과 교육

IV. 인구학적 배당(demographic dividend)

V. 보건부문 BLG사업의 SWOT 분석

VI. 결론

참고 문헌

[Annex 1] BLG 사업 사례 


\section{초록(Abstract)}

박근혜 대통령은 2015년 9월 27일 유엔 개발정상회의 기조연설을 통해 한국은 가장 취약한 상황에 처해있는 개도국 소녀들을 위해 보건·교육 ODA 사업인 '소녀들의 보다 나은 삶 구상을 내년에 공식 출범시키고, 향후 5 년간 2 억 불을 지원할 계획을 천명한 바 있다. 이에 따라 KOICA는 중장기전략 SDG KOICA 5대 브랜드 프로그램 중 하나로 소 녀들의 보다 나은 삶(Better Life for Girls)을 제안하였다.

개발도상국 인구의 $20 \%$ 이상을 차지하고 있는 여성청소년 집단은 개발도상국 사회에서 보건, 교육, 빈곤, 인권 등에서 가장 취약한 집단이다. 개발도상국의 여성청소년 생식보건 문제는 크게 여성청소년 임신 및 출산, 불안전 임신중절(unsafe abortion), 여성 폭력, $\mathrm{HIV/AIDS}$ 를 포함한 성매개질환, 유해한 관습(Harmful traditional practices), 영양장 애, 사고 등이다. 이러한 생식보건의 문제는 소녀들의 보다 나은 삶을 성취하기 위하여 해결해야 할 가장 핵심적인 문제이다.

여성청소년 임신은 고위험 임신의 하나로 모성과 신생아의 사망 및 질병 부담을 증가 시키는 요인이다. 나아가 개발도상국의 청소년 여성들은 10 대에 이른 결혼 및 출산으로 교육이 중단되어 개인의 사회경제적 역량을 강화할 기회를 갖지 못하는 동시에 계속되는 출산 및 육아의 부담으로 빈곤의 덫에서 빠져나올 수 없게 된다.

$\mathrm{WHO}$ 는 2011년 보건학적 측면에서 여성청소년 임신을 예방하기 위한 다음과 같은 6 개 지침을 제시한 바 있다. (1) 18 세 미만의 결혼을 감소시킨다, (2) 20 세 미만의 임신을 감소시킨다, (3) 필요한 피임 사용을 증가시킨다, (4) 강제된 성행위를 감소시킨다, (5) 불 안전한 임신중절을 감소시킨다, (6) 임신, 분만, 산후관리를 증가시킨다.

여성청소년들을 생식보건 서비스를 위하여 위한 청소년 친화적 서비스(Youthfriendly Services)를 제공하는 것이 필요하다. 청소년 친화적 서비스는 전반적인 성 및 생식건강 내용을 포함하되 프라이버시를 존중하고 상담하는 기능이 강조되어야 하며 무엇 보다도 필요한 적절한 의료적 법적 후송 서비스체계를 마련하여야 한다.

개발도상국의 조혼 및 여성의 높은 출산력은 국가의 급격한 피부양인구의 증가로 경제 성장의 저해 요인으로 작용하게 된다. 한국의 경우 적절한 경제개발 계획과 동시에 국가 차원의 강력한 가족계획 정책을 도입하였다. 이로 인하여 노동인구를 증가시키면서 피부 양인구를 감소시킨 인구학적 배당(demographic dividend) 효과로 경제성장의 견인차 역 할을 경험한 국가이다. 따라서 한국이 주도하는 BLG 구상은 단지 현재 여성청소년들의 보건, 교육, 고용의 개선 효과를 넘어 국가의 미래 경제성장을 촉진시킬 수 있는 인구학 적 배당 효과를 유도하여 궁극적으로 협력국의 빈곤을 퇴치하는 효과적이고 지속가능한 접근 방법이 될 수 있다. 


\section{I. 서론}

KOICA는 중장기전략 3대 핵심과제로서 (1) SDGs 이행전략 수립, (2) Post-2015 브랜드 사업 추진, (3) SDGS와 연계한 통합성과관리 체계구축 등을 발표하였고 이 중 SDG KOICA 5대 브랜 드 프로그램으로 (1) 새마을운동을 통한 지속가능하고 포용적인 개발(Saemaul Undong for Sustainable and Inclusive Development), (2) 소녀들의 보다 나은 삶(Better Life for Girls), (3) 모두를 위한 안전한 삶(Safe Life for All), (4) 보다 나은 삶을 위한 과학기술혁신(STI (Science, Technology \& Innovation) for Better Life), (5) 안전한 물과 청정에너지를 통한 기 후변화 대응(Safe Water \& Clean Energy for Climate Change Response)을 구체적으로 제시 하였다. 소녀들의 보다 나은 삶(Better Life for Girls, 이하 BLG)은 10대 여성청소년(10-20세) 을 대상으로 (1) 교육(Girls' Right to Education), (2) 보건(Girls' Right to Health), (3) 직업

(Girls' Right to Profession) 등의 지원분야를 제시하였으며 보건부문 지원분야로 "학교 내 청소 년 보건교육 강화 및 학교위생환경 구축” 및 “지역사회 및 의료시설 기반 여성청소년 친화적 성생 식보건 서비스 강화" 등을 예시한 바 있다(김인, 2015).

개발도상국 여성청소년 집단은 장차 미래의 인구를 출산을 담당할 중요한 핵심 집단이지만 개 발도상국 사회에서도 여성청소년 집단은 보건, 교육, 빈곤, 인권 등에서 가장 취약한 집단이다. 사하라이남 아프리카의 많은 국가에서 여성은 흔히 청소년기에 성폭력 또는 원치 않는 결혼 및 임신 등으로 교육이 중단되어 개인의 사회경제적 역량을 강화할 기회를 갖지 못하는 경우가 많 다. 이후 계속되는 임신 및 출산으로 인하여 여성과 출생아의 건강이 위협받게 되고 동시에 다자 녀의 과도한 양육비 부담으로 가구는 빈곤의 덫에서 빠져나올 수 없게 된다. 국가적으로도 이와 같은 여성의 높은 출산력은 피부양인구의 증가를 초래하여 경제성장의 저해 요인으로 작용하게 된다. 따라서 개발도상국의 소녀들의 조혼 및 다산의 문제는 소녀 개인의 보건 문제뿐만 아니라 그 가족의 빈곤 문제 나아가 국가 전체의 빈곤문제와 밀접하게 연관되어 있다. 이와 같이 BLG에 서 보건, 교육, 빈곤 문제는 서로 밀접하게 관련되어 있으며 특히 생식보건의 문제는 소녀들의 보 다 나은 삶을 성취하기 위하여 해결해야 할 가장 핵심적인 문제이다.

\section{II. 대상 인구}

“Girl”이라는 용어는 대개 젊은 여성을 지칭하는 단어이나 대상 연령 범위가 확실하지 않고 때 로는 성인 여성을 포함해서 광범위한 연령대의 여성들에게 사용하기도 한다. 따라서 UN을 포함 
한 국제기구에서는 생애주기적인 관점에서 특정 연령대의 젊은 인구들을 구별하는 용어로는 girl, boy 보다는 children, adolescent, youth, young people 등의 용어를 사용하여 왔다 (〈표 1〉 참조). 본 소고에서는 소녀들의 보건 문제를 adolescent girl, 즉 10대 여성들의 보건문제를 중심 으로 다루고자 한다.

〈표 1〉 청소년 인구들에 대한 UN기구들의 연령 기준

\begin{tabular}{c|c|c}
\hline Term & $\begin{array}{c}\text { Age Range } \\
\text { (years) }\end{array}$ & Source \\
\hline Children & $0-17$ & The UN Convention on the Rights of the Child \\
\hline Adolescent & $10-19$ & UNFPA, WHO, UNICEF \\
\hline Early Adolescent & $10-14$ & UNFPA, UNICEF \\
\hline Late Adolescent & $15-19$ & UNFPA, UNICEF \\
\hline Youth & $15-24$ & UNFPA, WHO, UNICEF \\
\hline Young People & $10-24$ & UNFPA, WHO, UNICEF \\
\hline
\end{tabular}

출처: 저자 작성

2011년 현재 전세계 청소년 인구는 남녀 합하여 약 12 억 (24세까지 포함할 경우 18억)명으로 전체 인구의 약 $18 \%$ 에 달하고 있다. 그러나 전체 인구 중 청소년이 차지하는 비중은 지역에 따라 달라 사하라이남 아프리카의 경우는 $23 \%$ 로 가장 높은 반면에 선진국의 경우 $12 \%$ 로 낮은 비중을 차지하고 있다(UNICEF, 2012). 전세계적으로 청소년 인구수는 최근 정체 또는 감소하고 있으나 사하라이남 아프리카의 경우는 유일하게 청소년 인구가 지속적으로 증가하고 있다(〈그림 1〉참조).

〈그림 1〉지역별 여성청소년 인구 변화 (1950-2050)

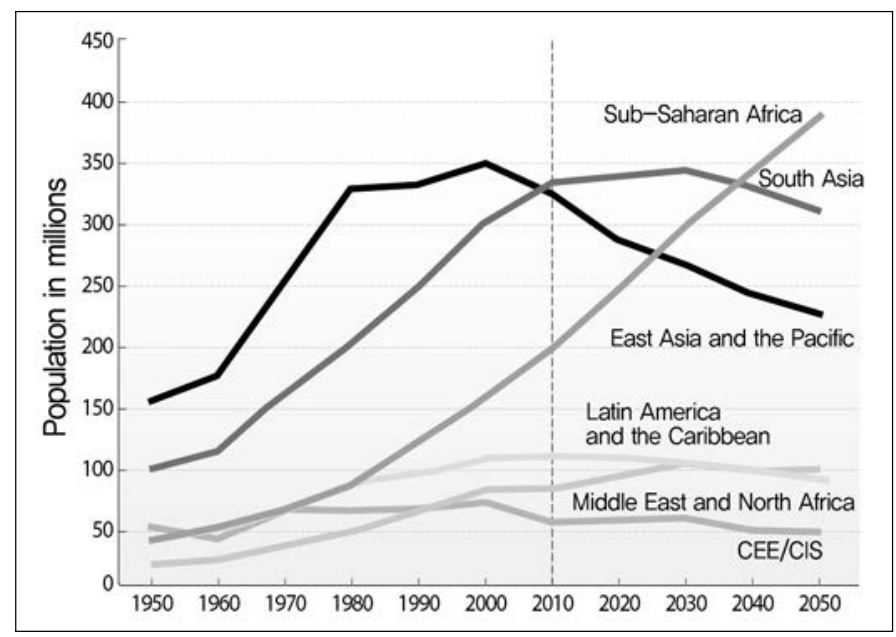

출처: UNICEF (2012) 
청소년들의 보건문제는 생식보건 문제 외에도, 영양장애, 교통사고, 비만, 흡연, 음주, 약물 남 용, 폭력, 정신건강, 자살 등 다양하며 국가에 따라 이들 문제들의 규모 및 양상이 다르다. 개발 도상국의 여성 청소년의 경우 무엇보다도 생식보건 문제가 가장 중요한 문제이며 따라서 국제보 건 관점에서 개발도상국의 여성청소년의 생식보건 문제는 항상 핵심적인 과제로 다루어왔다.

\section{III. 여성 청소년의 보건 문제들}

\section{1. 생식보건의 개념 및 영역}

생식보건(reproductive health)의 개념은 전통적인 모자보건에서 확대된 개념으로서 1994년 9월 이집트 카이로 인구 및 개발회의(International Conference on Population and Development) 에서 생식권(reproductive right) 개념을 도입한 것을 계기로 정립되었다. 인구 및 개발회의에서 는 '생식권이란, 모든 사람들이 원하는 시기에 원하는 터울로 원하는 수의 자녀들을 자유롭게 선 택할 수 있으며 최고 수준의 성생식보건(sexual and reproductive health)을 누리고 생식과 관 련된 의사결정에서 인권에 기초한 차별, 강압, 폭력에서 자유스러워질 수 있는 권리로 정의하였 다(UNFPA, 1994). 생식보건의 내용으로는 전통적인 임산부 및 신생아 관리, 가족계획 및 불임 서비스, 불안전한 임신중절 근절, 성병 퇴치, 성건강 증진 등의 핵심 영역을 기술하고 있다. 이와 같은 생식건강에 대한 목표는 MDG 5B에 포함된 바 있으며 SDGs에서도 드물게 Goal 3.7 및 Goal 5에 중복되어 강조되고 있어 여성청소년 생식보건 문제는 SDGs 시기에 더욱 중요한 과제가 되었다.

개발도상국의 주요 여성청소년 생식보건 문제는 다음과 같다.

- 여성청소년임신 및 출산

- 원치 않는 임신, 불안전 임신중절(unsafe abortion)

- 여성 폭력

- HIV/AIDS를 포함한 성병

- 유해한 관습(Harmful traditional practices)

- 영양장애, 비만, 사고, 정신질환, 흡연, 약물 남용 등 


\section{2. 여성청소년 임신 및 출산}

세계적으로 매년 15-19세 여성의 1,600만 명의 출산을 하고 있으며(15세 미만 백만 명) 이것 은 전체 출생아의 $11 \%$ 에 해당한다. 이와 같은 여성청소년 출산은 주로 중저소득국에서 발생하고 있다. 청소년 출산은 평균 1000 출생아당 49 이나 그 범위는 1-222로 지역에 따라 큰 차이를 보 이고 있으며 사하라이남 아프리카는 대부분 100이상으로 가장 높다(WHO, 2014). 40 60\% 개 발도상국의 여성청소년들은 18 세 이전에 결혼하거나 또는 동거생활을 하고 있다(UNICEF, 2011). 여성 청소년임신은 교육정도가 낮거나 빈곤계층일수록 높아 그 차이는 약 2 배 가량 높다 (UNFPA, 2016). 또한 사하라이남 아프리카 여성 청소년의 40 80\% 이상이 배우자 또는 동거자 이 외 성경험률을 보고하고 있다(UNICEF, 2011). 그러나 여성 청소년들의 피임 수요 미충족률 은 결혼 여성의 경우 $23 \%$, 동거의 경우 $41 \%$ 로 매우 높다(UNFPA, 2016).

10 대 임신은 고위험임신의 하나로 정상 임신과 비교하여 모성과 신생아의 건강에 사망 및 질 병부담 위험이 증가하는 것으로 보고하고 있다. 세계적으로 10 대 임신이 차지하는 규모는 전체 출산의 $11 \%$ 이나 임신 및 출산으로 인한 질병부담(disability-adjusted life years)은 전체의 $23 \%$ 에 달하고 있다. 또한 남미의 보고에 의하면 16 세 미만의 임신부는 20 대와 비교하여 모성사 망비가 4배 높은 것으로 보고되었다. 10대 임신은 불안전 임신중절로 종결되는 경우가 많아 중저 소득국가의 불안전 임신중절의 약 $14 \%$ 는 $15 \sim 19$ 세 발생하는 것으로 보고되었다. 10 대 임신은 또 한 빈혈, 말라리아, HIV/AIDS, 산후 출혈, 산후 우울증, 산과적 누관 등의 발생 위험이 높다 (WHO, 2015).

10 대 임신은 태아 및 신생아의 건강에도 부정적인 영항을 주고 있다. 20세 미만 임신의 사산 률은 20 대에 비하여 $59 \%$ 이상 높은 것으로 보고되었다. 10 대 임신은 신생아사망의 경우도 50-100\%이상 높은 것으로 나타났으며 또한 조산, 저체중아, 신생아 질식 등의 발생이 높아 이로 인한 사망 및 신경학적 장애의 위험이 높아진다. 그 이외에도 10 대 임신은 감염 이외에도 흡연, 음주 등 불량한 생활 습관등으로 인한 영향으로 출생아의 건강에 위험을 초래할 가능성이 높다 (WHO, 2015).

이와 같은 10 대 임신으로 인한 불량한 생식보건 문제를 예방하기 위하여 $\mathrm{WHO}$ 는 2011년 개발 도상국의 여성청소년임신을 예방하기 위한 지침을 제시한바 있다(WHO, 2011). 지침은 크게 6가 지 목표들을 제시하고 있으며 각의 목표에 대해 정책적 차원 및 개인, 가족, 지역사회 차원의 행 동지침을 마련하고 있다.

(1) 18 세 미만의 결혼을 감소시킨다

(2) 20 세 미만의 임신을 감소시킨다 
(3) 필요한 피임 사용을 증가시킨다

(4) 강제된 성행위를 감소시킨다

(5) 불안전 임신중절을 감소시킨다

(6) 임신, 분만, 산후관리를 증가시킨다

\section{3. 여성 청소년의 기타 보건 문제들}

현재 세계적으로 220 만 명의 청소년 HIV/AIDS 감염자가 있으며 사하라 이남 아프리카의 경 우 187 만 명의 청소년 감염자가 있고 이 중 $63 \%$ 는 여성 청소년이다. 여성 청소년들은 신체적으 로 HIV에 감염될 위험이 더 높으며 특히 최근에 개발도상국에서는 원조교제로 인한 성인 남성과 의 성관계로 인한 HIV감염이 증가하고 있다. 그러나 많은 청소년들은 HIV감염 예방에 대한 생식 보건 정보가 부족하고, 본인이 감염된 것을 인지하지 못하고 있으며 HIV검사를 받지 않고 있다 (UNICEF, 2012).

많은 여성 청소년들이 성폭력, 가정 폭력, 동료에 의한 폭력, 갱폭력 등 다양한 폭력에 시달리 고 있다. 성폭력을 경험한 청소년들은 원치 않는 임신 이외에도 성매개질환에 감염될 위험이 크 고, 우울증, 자살, 학업 중단 등으로 이어지게 된다. 가정폭력의 경우 대개 배우자에 의한 폭력이 많으며 이들 문제는 여성의 사회적 지위, 전통 및 사회규범과 관련된 것으로 다방면의 접근 전략 이 필요한 경우가 많다. 여성 청소년들의 기타 보건 문제로는 영양실조, 비만, 사고, 정신 질환, 음주, 흡연, 약물 남용 등이 있으나 이들 보건 문제들은 지역에 따라 다르다.

\section{4. 여성 성기 절단(Female Genital Cutting, FGC)}

여성 성기 절단(Female Genital Cutting, FGC)은 여성 성기 훼손(Female Genital Mutilation) 또는 여성 할례(Female circumcision)라고 명명되기도 하며 여성 성기의 일부 또는 전부를 잘라 내는 시술을 말한다. $\mathrm{FGC}$ 는 아프리카 북, 중부 및 동부 아프리카 지역에 광범위하게 시술되는 전통적인 시술로서 여성청소년들의 건강에 심각한 위험을 초래하는 시술이다. FGC는 소말리아 여성의 $98 \%$ 를 비롯하여 기니, 지부티, 이집트의 경우 $90 \%$ 이상의 여성들이 시술 받고 있다 (UNICEF, 2013). 이와 같은 시술은 의료인이 아닌 마을의 무속인들이 비위생적인 방법으로 시 술하기 때문에 시술시 출혈, 감염 등으로 고통을 겪거나 심하면 사망하는 경우도 있다. FGC는 시술직후 뿐만 아니라 중장기적으로 통증, 감염 등의 위험이 수반될 뿐 아니라 성활동 시작시에 시술부위의 큰 고통을 겪게 되고 나아가 정상적이 성활동이 어렵게 된다. FGC를 받은 임신부는 
분만시 난산 발생 위험이 높아 산모나 출생아의 건강을 위태롭게 하거나 출산 후에 누관 등의 합 병증 발생이 증가한다. 아프리카 지역의 $\mathrm{FGC}$ 시술은 뿌리 깊은 문화적 전통에 기인한 것이기 때 문에 이로 인한 피해를 예방하기 위해서는 보건 이외에도 인권적, 법률적, 문화인류학적 접근이 병행되어야 한다.

\section{5. 청소년 친화적 서비스(Youth-friendly Services)}

대부분의 여성청소년들은 성인 여성들과 같은 보건의료기관을 이용하기에 어려움을 호소하기 때문에 여성청소년들을 생식보건 서비스를 위한 청소년 친화적 서비스(Youth-friendly Services) 를 제공하는 것이 필요하다(WHO, 2012). 청소년 친화적 서비스는 성 및 생식건강 정보 제공, 피임 방법 제공, 상담, 산전 및 분만관리, HIV를 포함한 성병 예방 등의 내용을 포함하되 프라이 버시를 유지하며 상담하는 기능이 강조되어야 하고 필요한 적절한 의료적 법적 후송 서비스체계 를 마련하여야 한다. 청소년 친화적 서비스(Youth-friendly Services)를 기획, 수행, 평가의 전 단계에서 여성청소년들의 적극적인 참여가 바람직하다.

생식보건학적 관점에서 우선순위가 높은 대상 여성청소년들은 다음과 같다.

- 결혼한 여성청소년

- 폭력피해 여성청소년

- 정규 교육 미이수 또는 중단자

- $\mathrm{HIV}$ 감염 여성

- 생식보건 정보에 접근하지 못하는 여성청소년

- 생식보건 서비스에 접근하지 못하는 여성청소년

\section{6. 생식보건과 교육}

MDGs의 보편적 초등교육 목표에 힘입어 세계적으로 초등학교 취학률은 평균 $90 \%$ 에 달하고 있으나 중등학교의 경우 아직 평균 $60 \%$ 에 달하며 사하라이남 아프리카의 경우 중등학교 등록률 은 전반적으로 $30 \%$ 미만이다. 여성 청소년들의 지속적인 학교생활은 10 대 임신 및 출산 예방과 서로 밀접하게 관련된다. 개발도상국의 여성 청소년들은 학교 수업이 중단되자마자 성 활동 시작 및 10 대 임신으로 진행하거나 그 반대로 임신으로 인한 학업 중단으로 인하여 학교생활이 중단된 다. 이와 같은 10 대 임신 및 학업 중단은 임신 그 자체로 인한 건강 위험 및 육아 부담뿐만 아니 라 학업 중단으로 인한 여성 개인의 교육기회 상실로 이어져 궁극적으로 빈곤의 악순환에서 빠져 
나오지 못하게 된다. 따라서 10대 임신을 예방하기 위해서도 여성 청소년들의 지속적인 취학이 중요하며 반대로 임신으로 인하여 일시 학업이 중지돤 경우에도 출산 후 가능한 학교로 복귀할 기회를 제공하거나 또는 학교 밖 최소한의 직업 교육 등으로 여성청소년의 사회경제적 역량강화 를 통하여 인적 자산을 확보할 기회를 제공하여야 한다. 따라서 BLG은 보건, 교육, 직업훈련 등 다분야 접근이 필수적이며 무엇보다도 인권에 기초한 성평등적 접근 원칙을 견지하는 것이 필요 하다.

제 I 장

개

\section{IV. 인구학적 배당(demographic dividend)}

사하라 이남 아프리카를 포함한 많은 개발도상국에서는 아직도 합계출산력이 높으며 이로 인한 높은 인구증가율로 인하여 인구의 피라미드 구조가 지속되고 있다. 이와 같은 인구구조는 매년 부양해야 될 인구가 급증하므로 취약한 개발도상국의 국가 재정에 큰 부담이 되고 있다. 한국의 경우 적절한 경제개발 계획과 동시에 강력한 가족계획 정책으로 인한 시기적절한 출산력 감소가 경제성장의 원동력이 되었다. 즉, 한국의 경우, 적절한 수준의 출산력 감소가 상대적으로 노동인 구를 증가시키는 동시에 피부양인구를 감소시키는 효과를 낳았다. 이를 통해 한국은 저축증가와 교육기회 확대로 인한 양질의 인적자산을 확보할 수 있게 됨에 따라, 이와 같은 인구학적 배당 (demographic dividend)이 한국의 경제성장의 견인차 역할을 하였다(Gribble, 2012)(〈그림 2〉 참조). 사하라 이남 아프리카의 많은 국가에서는 아직도 높은 출산력이 유지되고 있으며 그 주된 원인은 여성청소년들의 이른 성활동 및 높은 출산율 때문이다. 이론적으로 여성청소년들의 출산 연령을 일년만 늦출 수 있어도 이로 인한 후속 세대의 가임 연령기간에 그대로 반영되므로 전반 적인 출산력 저하 효과는 크게 나타난다. 또한 여성의 출산 연령 지연은 저출산으로 인한 피부양 가족 감소 및 이로 인한 저축 증가 효과와 더불어 여성 자신의 사회경제적 역량강화를 통한 인적 자산 형성에 기여하는 소위 소녀인구 배당(girl dividend) 효과를 발생할 수 있어 국가의 경제성 장을 촉진할 수 있는 원동력이 될 수 있다. 이와 같은 관점에서고 $\mathrm{BLG}$ 구상 사업의 영향은 단지 현재 세대의 보건, 교육, 고용의 개선 효과를 넘어 한 국가의 미래 경제성장을 촉진시킬 수 있는 인구학적 변화를 유도하여 궁극적으로 협력국의 빈곤을 퇴치하는 효과적이고 지속가능한 접근 방 법이 될 수 있다. 
〈그림 2〉 한국의 인구학적 배당

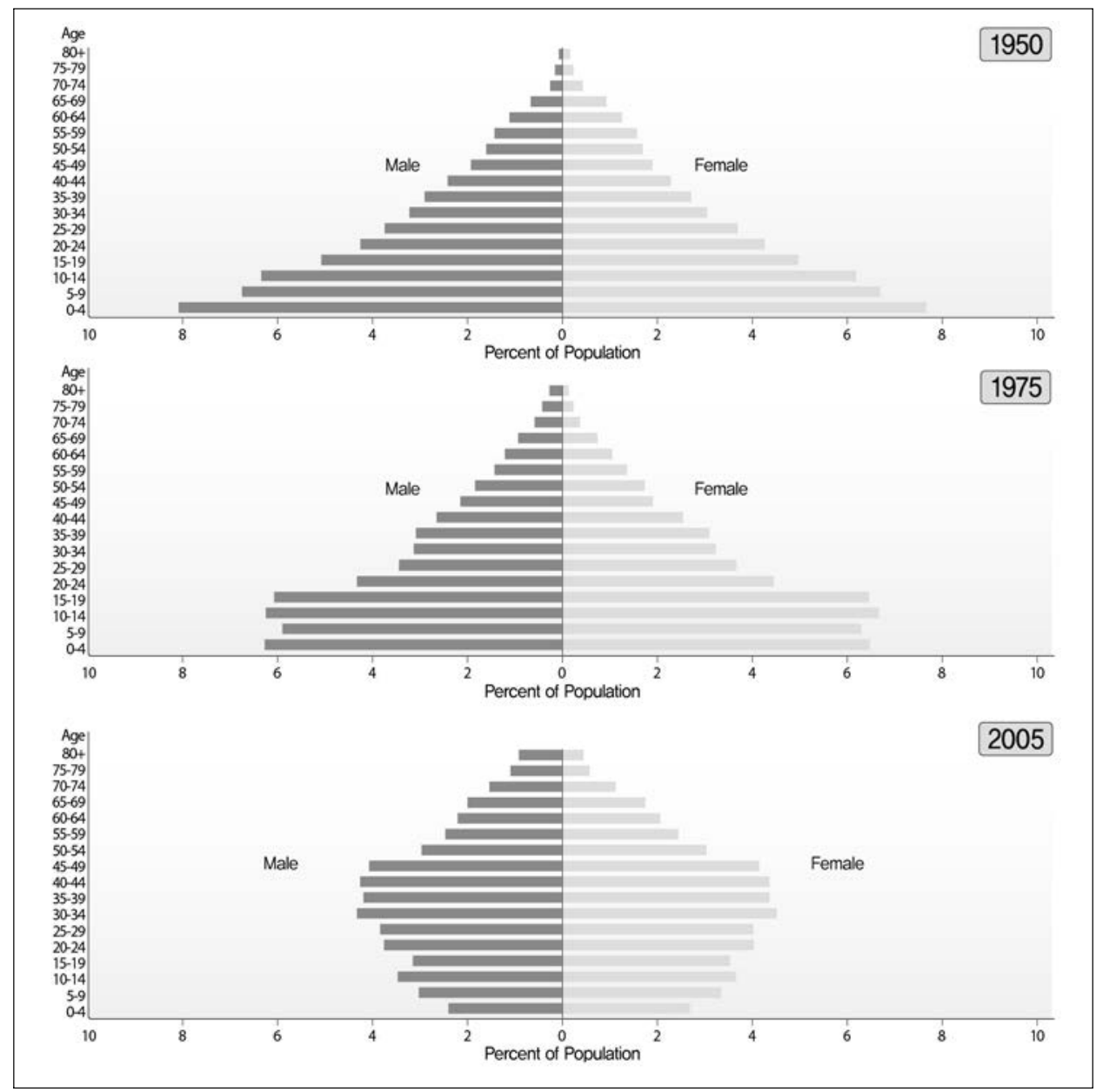

출처: Gribble, JN (2012)

\section{V. 보건부문 BLG사업의 SWOT 분석}

보건 부문에서 실시하는 BLG사업에 대한 SWOT분석 결과는 다음과 같이 나누어볼 수 있다.

\section{1. 강점}

○한국은 과거 성공적인 가족계획 및 모자보건사업을 수행한바 있으며 이로 인한 인구학적 배 당 효과로 급격한 경제성장을 달성한 모범국가이다. 
○ 국내 산부인과, 소아과 등 양질의 임상의료 인력이 풍부하다.

○ KOICA는 그동안 모자보건, 교육 및 직업 훈련 사업을 통하여 경험을 축적하고 있다.

\section{2. 약점}

안국의 성공적인 가족계획사업을 경험한 고출산시대의 인구 및 생식보건 전문인력은 대부분 은퇴하여 현재 활동하지 않고 있다.

○ 현재 생식의학 임상 인력은 확보되어 있으나 공중보건으로서의 생식보건 전문가가 부족하다.

$\circ \mathrm{KOICA}$ 는 새마을사업 등을 수행한 바 있으나 아직 다분야사업 및 국제기구 및 현지 NGO 들과의 협력 경험이 아직 부족하다.

\section{3. 기회}

○ BLG 구상은 지속가능한 개발을 위해 보건, 교육, 빈곤 등 관련 다분야 접근방식을 통하여 지속가능한 빈곤 퇴치를 추구하는 SDG 정책방향과 일치하는 사업이다.

○ BLG 사업은 인구학적 배당을 유도하여 협력국의 빈곤을 퇴치하는 효과적이고 근본적인 접 근 방법이다.

○ 인터넷, 휴대폰 등의 정보기술 변화로 인하여 개발도상국 여성청소년들의 의식 변화가 빨라 지고 있다.

\section{4. 위협}

애발도상국의 여성청소년 인구가 매년 폭발적으로 증가하고 있다.

○ BLG의 핵심 문제들은 협력국의 사회문화적 배경과 밀접하게 연관되어 있어 이를 변화시키 기가 쉽지 않다.

$\circ \mathrm{BLG}$ 사업은 이해관계자 및 관련 기관들이 많다. 


\section{VI. 결론}

개발도상국 인구의 $20 \%$ 이상을 차지하고 있는 여성청소년 집단은 개발도상국 사회에서 보건, 교육, 빈곤, 인권 등에서 가장 취약한 집단이다. 개발도상국의 여성청소년 생식보건 문제는 크게 여성청소년 임신 및 출산, 불안전 임신중절(unsafe abortion), 여성 폭력, HIV/AIDS를 포함한 성병, 유해한 관습(Harmful traditional practices), 영양장애, 사고 등이다. 이러한 생식보건의 문제는 소녀들의 보다 나은 삶을 성취하기 위하여 해결해야 할 가장 핵심적인 문제이다. 개발도 상국의 많은 국가에서 청소년여성들은 10 대에 이른 결혼 및 출산으로 모성과 신생아의 사망 및 질병 부담이 중가할 뿐만 아니라 여성 청소년 자신의 교육이 중단되어 개인의 사회경제적 역량을 강화할 기회를 갖지 못하는 동시에 계속되는 출산 및 육아의 부담으로 빈곤의 덫에서 빠져나올 수 없게 된다.

국가적인 차원에서 개발도상국의 조혼 및 여성의 높은 출산력은 피부양인구의 증가로 경제성장 의 저해 요인으로 작용하게 된다. 한국의 경우 적절한 경제개발 계획과 동시에 강력한 가족계획 정책으로 인한 시기적절한 출산력 감소로 노동인구를 증가시키면서 피부양인구를 감소시킨 인구 학적 배당(demographic dividend) 효과로 경제성장의 견인차 역할을 경험한 국가이다. 따라서 한국이 주도하는 BLG 구상은 단지 현재 세대의 보건, 교육, 고용의 개선 효과를 넘어 한 국가의 미래 경제성장을 촉진시킬 수 있는 인구학적 변화를 유도하여 궁극적으로 협력국의 빈곤을 퇴치 하는 효과적이고 지속가능한 접근 방법이 될 수 있다. 


\section{〈참고문헌〉}

김인. 2015. “KOICA 중장기전략에서의 SDGs 주류화 방안" 『국제개발협력지』2015년 제4호. 성남: 한국국제협력단. pp.3-35

한국국제협력단. 2016. "UNFPA 우간다 여성청소년의 더 나은 삶을 위한 십대임신 예방 및 사회경제적 역량강화 사업 사전타당성 조사 보고” 내부문서. 성남: 한국국제협력단

Gribble, JN. 2012. “South Korea’s Demographic Dividend” posted on Population Reference Bureau website in November 2012, available at http://www.prb.org/Publications/Articles/2012/south-korea-population.aspx UNICEF. 2011. "The State of the World's Children 2011: Adolescence an age of opportunity". New York: UNICEF, available at http://www.unicef.org/adolescence/ files/SOWC_2011_Main_Report_EN_02092011.pdf

2012. "Progress for Children: A report card on adolescents". New York: UNICEF, available at http://www. unicef.org/publications/files/Progress for_Children___No._10_EN_04232012.pdf

2012. "Making health services adolescent friendly: Developing national quality standards for adolescent friendly health services”. Geneva: WHO, available at http://www.who.int/maternal_child_adolescent/documents/adolescent_friendly_ services/en/

2013. "Female Genital Mutilation/Cutting: A statistical overview and exploration of the dynamics of change". New York: UNICEF, available at http://www.unicef.org/media/files/UNICEF_FGM_report_July_2013_Hi_res.pdf

2015. Adolescent pregnancy, available at http://www.who.int/maternal child_adolescent/topics/maternal/adolescent_pregnancy/en/

2016. "Universal access to reproductive health: progress and challenge".

New York: UNFPA, available at https://www.unfpa.org/sites/default/files/ pub-pdf/UNFPA_Reproductive_Paper_20160120_online.pdf

UNFPA. 1994. "The Programme of Action" Adapted at International Conference on Population and Development, Cairo 5-13 September, 1994, available at https://www.unfpa.org/sites/default/files/event-pdf/PoA_en.pdf 
WHO. 2011. "Guidelines on Preventing Early Pregnancy and Poor Reproductive Outcomes Among Adolescents in Developing Countries” WHO, Geneva: WHO, available at http://www.who.int/immunization/hpv/target/preventing_early_ pregnancy_and_poor_reproductive_outcomes_who_2006.pdf . 2014. “Adolescent pregnancy". Fact sheet $N^{\circ} 364$, posted on WHO Country Office for Thailand on 25 February 2014, available at http://www.searo. who.int/thailand/factsheets/fs0001/en/ 


\section{[Annex 1] BLG 사업 사례5)}

\section{1. 대상지역: 우간다 14 개 군}

Eastern Uganda (Amuria, Bududa, Butaleja, Iganga, Kapchorwa, Katakwi, Mayuge), Karamoja Region (Abim, Amudat, Kaabong, Kotido, Moroto, Nakapiripirit, Napak)

\section{2. 현황 (전체 임신 대비 비율)}

(단위: \%)

\begin{tabular}{c|c}
\hline 여성청소년 임신율 & $29.7 \sim 30.6$ \\
\hline 시설분만율 & $27.0 \sim 67.0$ \\
\hline 피임실천율 & $7.4 \sim 27.7$ \\
\hline 피임 미충족 필요 & $20.5 \sim 41.9$ \\
\hline 여성초등학교 순등록률 & $49.3 \sim 89.3$ \\
\hline 여성 중등학교 순등록률 & $7.5 \sim 20.7$ \\
\hline
\end{tabular}

\section{3. 사업명}

○ 국문명: 우간다 여성청소년의 더 나은 삶을 위한 십대 임신 예방 및 사회경제적 역량강화 사업

영문명: Better Life for Girls(BL4G): Preventing adolescent pregnancy and reaping the girl effect dividend in Karamoja and Eastern regions of Uganda

\section{4. 사업 기간}

○ 2016.3-2018.9 (약 2년 6개월)

\section{5. 사업 규모}

○6백8십만 불 (한국 부담: 5 백만 불)

5) 출처: KOICA (2016) "UNFPA 우간다 BL4G 사전타당성 조사 보고서" 


\section{6. 대상인구 및 수혜자}

(단위: 명)

\begin{tabular}{c|c|c}
\hline 구 분 & 대 상 & 인 원 \\
\hline 1차 수혜자 & 여성청소년(10 19세) & 366,072 \\
\hline \multirow{4}{*}{ 2차 수혜자 } & 여성청소년(10 19세) & 357,622 \\
\cline { 2 - 3 } & 보건의료인력 & 840 \\
\cline { 2 - 3 } & 교사 (초등, 중등) & 750 \\
\cline { 2 - 3 } & 부모 & 200,000 \\
\cline { 2 - 3 } & 지역주민 & $3,000,000$ \\
\hline
\end{tabular}

\section{7. 수행기관}

우간다 UNFPA

엽력기관: Uganda Ministry of Health, Ministry of Education and Sports, Ministry of Gender, Bangladesh Rural Advancement Committee (BRAC), Straight Talk Foundation, Reproductive Health Uganda (RHU), Inter-Religious Council of Uganda (IRCU), and Reach a Hand Uganda (RAHU) and Population Media Center(PMC)

\section{8. 사업 목적}

: 우간다 14 군 지역 여성청소년들의 건강 및 사회경제적 역량 증진

에부목적1: 여성청소년들의 적절한 성생식보건 정보 및 서비스 접근성 증가

○ 세부목적2: 여성청소년들의 사회경제적 역량 강화

\section{9. 사업 구성}

○ 사업지역 교육위원회가 성생식보건 프로그램을 감시 및 모니터링 하도록 지원

○ 초중등학교 교사들을 대상으로 ICT(SafePal, Global Mobile)기반의 성생식보건 정보 및 서 비스 접근성 증진을 위한 거점인력 확보

학교 소녀클럽의 생리 중 위생증진 활동 지원

악교 밖 여성청소년 대상 Empowerment and Livelihood for Adolescent(ELA)클럽 결성 및 생활기술교육지원 
오버넌요원 (CHW포함)들에게 상담을 포함한 여성청소년 친화적 적절한 성생식보건 서비스를 제공할 수 있도록 훈련

옹공장소에 여성청소년 친화적 성생식보건 정보 및 서비스를 제공

○ 지역주민들이 여성청소년의 교육 및 역량 강화에 투자하도록 고취하는 매스미디어 캠패인

○ 10대 임신예방을 위한 Male Action Groups 모임의 활성화 지원 